\title{
Bacias hidrográficas transfronteiriças: saneamento e saúde ambiental sem fronteiras
}

\section{Transboundary river basins: sanitation and environmental health without borders}

Maurício Pinto da Silva1, Rafaela Facchetti Assumpção², Débora Cynamon Kligerman²
1 Universidade Federal de Pelotas (UFPEL) - Pelotas (RS), Brasil.

mauriciomercosul@gmail.

com

2 Fundação Oswaldo Cruz (Fiocruz), Escola Nacional de Saúde Pública Sergio Arouca (Ensp) - Rio de Janeiro (RJ), Brasil.
DOI: $10.1590 / 0103-1104202012418$

RESUMO A interconexão de temas como ambiente, saúde e saneamento está cada vez mais central na sociedade. As preocupações decorrem da forma irresponsável das relações humanas estabelecidas com o ambiente, caracterizadas pelo modo desmedido e inconsequente do uso dos bens da natureza. Tal conduta tem tido impactos ambientais imprevisíveis, que, na maioria das vezes, extrapolam as fronteiras entre Estados nacionais. Nesse contexto, as bacias hidrográficas transfronteiriças caracterizam-se por compreenderem dois ou mais Estados, constituindo-se uma área delimitada para o planejamento, a gestão, a cooperação no campo do saneamento. O estudo teve por objetivo suscitar o debate sobre temas como saneamento e a saúde ambiental em bacias hidrográficas transfronteiriças. Em termos metodológicos, elegeram-se a revisão bibliográfica e o estudo documental, tendo como objeto de análise o Tratado Brasil-Uruguai da Bacia Hidrográfica Mirim-São Gonçalo. Os resultados apontam para a necessidade de ampliação do conhecimento sobre os instrumentos de gestão em bacias hidrográficas transfronteiriças. A articulação sociopolítica institucional entre os atores deve ser intensificada, com ênfase em uma abrangência transfronteiriça, permitindo a adoção de planos de bacia integrados, bem como de estratégias de ação em diferentes demandas, dirimindo conflitos e gerando um cenário de reciprocidade, valorização da cidadania e sustentabilidade ambiental.

PALAVRAS-CHAVE Recursos hídricos. Áreas de fronteira. Cooperação internacional. Saneamento. Saúde ambiental

\begin{abstract}
The interconnection of themes such as environment, health and sanitation are increasingly central to society. The concerns arise from the irresponsible form of human relations established with the environment, characterized by the excessive and inconsequential way of using the goods of nature. Such conduct has had unpredictable environmental impacts, which, in most cases, go beyond the borders between national states. In this context, transboundary river basins are characterized by comprising two or more States, constituting a defined area for planning, management, cooperation in the field of sanitation. The study aimed to raise the debate on topics such as sanitation and environmental health in transboundary watersheds. In methodological terms, the bibliographic review and the documentary study were chosen, having as object of analysis the Brazil-Uruguay Treaty of the Mirim-São Gonçalo Hydrographic Basin. The results point to the need to expand knowledge about management instruments in transboundary watersheds. The institutional socio-political articulation between the actors must be intensified, with an emphasis on cross-border coverage, allowing the adoption of integrated basin plans, as well as action strategies in different demands, settling conflicts and generating a scenario of reciprocity, appreciation of citizenship and environmental sustainability.
\end{abstract}

KEYWORDS Water resources. Borders areas. International cooperation. Sanitation. Environmental health. 


\section{Introdução}

Os temas relacionados com o meio ambiente e com a saúde tornam-se cada vez mais centrais para cientistas de diversas áreas e para segmentos da sociedade, comprometidos com a sustentabilidade da vida no planeta. Estas preocupações decorrem da forma irresponsável das relações estabelecidas com o meio ambiente, caracterizadas pelo modo desmedido e inconsequente do uso dos bens naturais. Tal conduta provoca impactos ambientais imprevisíveis, que, na maioria das vezes, extrapolam as fronteiras entre os Estados nacionais.

Assim, de forma incipiente, surge entre os pioneiros da questão ambiental a preocupação referente às implicações das atividades produtivas sobre os seres vivos e o meio ambiente, este último compreendido pela qualidade do ar, do solo, das águas e pela conservação da natureza. Na Alemanha, por exemplo, a questão premente na década de 1920 era com a contaminação atmosférica no Vale do Reno e seu impacto sobre florestas; no Japão dos anos 1950, os efeitos do envenenamento por mercúrio em Minamat, por cádmio em Toyama e dióxido sulfúrico em Yokkaichi'.

Nesse sentido, os efeitos ambientais transfronteiriços e globais ganham visibilidade com a publicação do livro The Silent Spring, de Rachel Carson (1962), juntamente com as novas descobertas cientificas gerando ameaças decorrentes da degradação ambiental, relacionadas com a saúde humana, tais como: radiação, resíduos tóxicos de metais pesados, hidrocarbonetos clorinados na água e emissões atmosféricas, que passam a ter expressividade nos debates da comunidade internacional. $\mathrm{O}$ rio Reno é emblemático, pois

[...] os problemas dos rios internacionais não são sempre semelhantes. Em primeiro lugar, isto resulta do traço das fronteiras e do rio. A fronteira pode ser perpendicular ao curso, com um país à jusante e um país à montante; ela pode seguir o curso do rio, com uma margem em um país e outra no outro. Pode existir uma combinação dessas duas configurações - o rio Paraguai é em primeiro lugar um rio fronteira entre Brasil e Bolívia, depois entre o Brasil e o Paraguai; adentra no Paraguai e também serve de fronteira entre o Paraguai e a Argentina. Depois da confluência com o Paraná, entra na Argentina. O caso do Reno é semelhante, porém mais complicado: ele tem um traço suíço, pois serve de fronteira entre Alemanha e Suíça, mas com incursões no território deste último. Ele serve depois de fronteira entre Alemanha e França; entra na Alemanha e, em seguida, na Holanda2(47).

Nesse contexto, o processo de globalização, por exemplo, produz uma série de paradoxos. A industrialização e a urbanização nos países denominados emergentes desequilibram e alteram profundamente as relações entre sociedade e natureza, demandando ações pragmáticas em relação às políticas públicas, à gestão e ao planejamento em áreas como saúde e saneamento, especialmente em bacias hidrográficas transfronteiriças. Os desafios a serem enfrentados permeiam toda a organização social, desde a produção, a distribuição e o consumo de bens e serviços até as formas de estruturação do Estado e suas políticas públicas relativas ao meio ambiente, à saúde e ao saneamento.

De acordo com levantamento da Unesco, há, no mundo, 263 bacias hidrográficas com corpos d'água transfronteiriços inseridos em 145 países.

Trinta e três Estados encontram-se totalmente inseridos em bacias hidrográficas transfronteiriças ou possuem mais de $90 \%$ de seu território contido em áreas de drenagem de rios compartilhados com outros países ${ }^{3(22)}$.

Na América do Sul, com hidrografia de águas abundantes, há 37 bacias hidrográficas com recursos hídricos contínuos ou contíguos, e todos os 13 países da região compartilham algum corpo hídrico. "O território do Paraguai, por exemplo, encontra-se totalmente dentro de uma bacia com rios transfronteiriços"3(22). 
O Brasil possui grandes bacias como a Amazônica (Peru, Colômbia, Venezuela, Equador, Bolívia e Guiana) e do Prata (Bolívia, Paraguai, Paraná e Uruguai), além de duas pequenas bacias nas quais se encontram rios-símbolo dos limites do Brasil - o Oiapoque e o Arroio Chuí - respectivamente nas bacias Costeiras do Norte (no Amapá, fronteira com a Guiana Francesa) e na bacia da Lagoa Mirim-São Gonçalo delimitando as divisas com o Uruguai ${ }^{3}$.

Dentre as principais ações de abrangência internacional em que o Brasil é protagonista, destaca-se a Organização do Tratado de Cooperação Amazônica (OTCA), no qual o potencial hídrico é compartilhado pelos países da Bacia Amazônica, e as ações de cooperação são frequentes e necessárias. Além do OTCA, há a participação na Convenção sobre as Zonas Úmidas de Importância Internacional Especialmente Enquanto Habitat de Aves Aquáticas, também conhecida como convenção de Ramsar, que tem por objetivo a proteção e manejo sustentável de áreas úmidas.

As fronteiras do Prata, que compreendem cinco países sul-americanos - Argentina, Bolívia, Brasil, Paraguai e Uruguai -, foi uma região de disputas territoriais seculares, no entanto, os grandes rios prevaleceram na demarcação dos limites internacionais. Assim, a gestão das águas fronteiriças e transfronteiriças, por exemplo, tornam-se cada vez mais desafiadora para os diferentes países.

Destarte, o presente estudo busca suscitar o debate acerca das bacias hidrográficas transfronteiriças e sua relação com os desafios ao saneamento sem fronteiras. $\mathrm{O}$ recorte territorial de bacia hidrográfica para o Brasil, um país com dimensões continentais, implica enormes esforços no campo diplomático, econômico e social. Esse espaço singular é materializado em $15.719 \mathrm{~km}$, área correspondente a cerca de $27 \%$ do território nacional, aproximadamente 10 milhões de habitantes e 588 municípios ${ }^{3}$.

De forma complementar, o estudo tem como objeto de análise o Tratado
Brasil-Uruguai da Bacia Hidrográfica Mirim-São Gonçalo, localizada nos limites internacionais entre o Brasil e o Uruguai, considerada transfronteiriça, com regime de águas compartilhadas (Tratado de Limites de 1909 e Tratado da Lagoa Mirim de 1977), declarada pela Unesco como Reserva da Biosfera.

\section{Metodologia}

Em termos metodológicos, o presente artigo é baseado em uma pesquisa exploratória devido à investigação sobre o tema saneamento e saúde em áreas fronteiriças e transfronteiriças, tendo como métodos a revisão bibliográfica e o estudo documental. A revisão bibliográfica possibilitou o aprofundamento de conceitos, como: saneamento, saúde ambiental, fronteira e bacias hidrográficas transfronteiriças.

Esta análise complementou, de certa forma, os ensaios conceituais trazidos no artigo, caracterizando, assim, uma abordagem qualitativa em saúde. Nesse sentido,

[...] além de permitir desvelar processos sociais ainda pouco conhecidos referentes a grupos particulares, propicia a construção de novas abordagens, revisão e criação de novos conceitos e categorias ${ }^{4(57)}$.

Em um segundo momento, a pesquisa documental possibilitou melhor análise do Tratado Brasil-Uruguai da Bacia Hidrográfica MirimSão Gonçalo, localizada na fronteira entre os dois países. A referência metodológica em saúde utilizada indica um debate qualitativo na área da saúde, tanto no campo teórico quanto no campo metodológico, sendo recomendável em estudos da

[...] história, das relações, das representações, das crenças, das percepções e das opiniões, produtos das interpretações que os humanos fazem a respeito de como vivem, constroem seus artefatos e a si mesmos, sentem e pensam ${ }^{4(57)}$. 


\section{Fronteira ebaciahidrográfica: duas faces de uma mesma moeda?}

Os limites (a fronteira) se constituíram como resultado da divisão de terras férteis (primitiva fase egípcia). Datados do século XIII A.C., como por exemplo, o Tratado Egípcio-Hitita de Aliança (assinado por Ramsés II e Hattussil) não mencionava limites ${ }^{5(20)}$.

Foi por volta do século III D.C. que a fixação de limites foi caracterizada como uma estratégia. A ideia de obstáculo natural surgiu com a expansão do império romano (os rios Reno e Danúbio) e as divisões lindeiras da Idade Média (a França era limitada por quatro rios).

Há uma variedade de conceitos e definições inserida no termo 'fronteira' que varia de acordo com os Estados Nacionais. A fronteira, em uma perspectiva política, aparece com o surgimento do Estado absoluto, ao agregar elementos como povo e nação, aparecendo também seu elemento valorativo, ou seja, a jurisdição, tendo sua base de atuação delimitada pelas fronteiras. Nesse sentido, entre as principais caracterizações para a fronteira, encontram-se afirmações, como: lacunas de um país para outro; áreas complicadas de viver, convívio social praticamente inexiste ou baixa densidade de relações sociais.

A concepção de fronteira está nitidamente associada às disputas territoriais, controle pelo Estado, perda da liberdade de ir e vir e também às guerras. A fronteira traz em seu bojo uma diversidade de sentidos e aponta para os significados construídos em distintas realidades históricas. Em uma visão mais crítica, é concebida não somente como um fato geográfico ou uma representação cartográfica, mas um fato histórico e de relacionamentos sociais.

Autores clássicos da geografia política como Friedrich Ratzel (1890) vincularam o conceito de fronteira ao de Estado, sendo a fronteira entendida como princípio para a expansão e crescimento dos Estados; Frederick Jackson Turner (1893) tomou a fronteira como elemento central de sua análise interpretativa da história norte-americana. Nesse período, comumente pensava-se a fronteira utilizando a noção de soberania, com enfoque na sua dimensão expansionista.

É importante destacar que esse ideário busca definir o patrimônio do Estado, em que a soberania é legitima e para onde os investimentos devem ser direcionados, entretanto, essas delimitações não são absolutas nem são capazes de impedir as interações sociais, culturais, os fenômenos naturais, as práticas religiosas e, especialmente, a propagação de epidemias, advindas, muitas vezes da inexistência e ou fragilidade do sistema de saúde e da infraestrutura de saneamento instalada nessas áreas.

Nesse sentido,

[...] as origens políticas do conceito de fronteira estão associadas à própria formação dos Estados-nacionais, que no processo de consolidação tiveram, e ainda tem de demarcar claramente linhas divisórias, visto implicar da ordem, da norma e do poder instituído5(29).

O termo fronteira

[...] implica, historicamente, aquilo que sua etimologia sugere - o que está na frente. $\mathrm{A}$ origem histórica da palavra mostra que seu uso não está associado a nenhum conceito legal e que não é um conceito essencialmente político ou intelectual. Nasceu como um fenômeno da vida social espontânea, indicando a margem do mundo habitado6(41).

"É bastante comum considerar os termos fronteira e limite como sinônimos. Existem, contudo, diferenças essenciais entre eles e que escapam ao senso comum"7(41). As fronteiras, em geral, nascem como áreas periféricas, engendram desigualdades, portanto, como lugar; 
a fronteira é o envoltório de um conjunto de instituição, práticas, sujeitos e modos de vida que se dão de forma particular naquele lugar, e não em outro.

As fronteiras estão presentes no imaginário social como limite, aparecendo como naturalizadas. Entretanto, elas são mais do que isso, pois ao mesmo tempo em que impedem, permitem a passagem ${ }^{\mathbf{8}(69)}$.

"A fronteira tem sua orientação para fora (exterior) e limite é uma linha de separação definida"9(69). O limite pode ser compreendido como "a linha onde começa a soberania de um Estado e termina a de outro"10(13-14). É a linha que circunscreve o território do Estado. Como limite é uma linha, consequentemente só tem uma dimensão que é o seu comprimento. As fronteiras também podem ser denominadas como

[...] amplas franjas territoriais de um lado e de outro das linhas de demarcação geográficas políticas, na qual convivem populações com particularidades próprias que as diferenciam de outras partes dos territórios nacionais 11(60).

Historicamente, os países aplicaram regulações específicas para suas áreas de fronteira, geralmente qualificadas como "zonas" ou "faixas de segurança"12(174), cujos critérios inibiram e restringiram a implementação de projetos de integração. No Brasil, não foi diferente, a fronteira foi concebida como área de segurança nacional a ser protegida de inimigos e invasões. Assim, é importante destacar que

[...] as linhas geopolíticas delimitam, na verdade, as ações governamentais, o planejamento e a manutenção dos serviços públicos, mas, não separam os valores culturais, os laços familiares, as trocas de experiências, nem impedem as práticas ilegais, nem as epidemias e nem as vulnerabilidades sociais'13(91).

Nesse contexto,
[...] a territorialidade, além de incorporar uma dimensão estritamente política, diz respeito também às relações econômicas e culturais, pois está intimamente ligada ao modo como as pessoas utilizam a terra, como elas próprias se organizam no espaço e como elas dão significado ao lugar14(03).

No rastro desse raciocínio, o território não se resume a uma variável estratégica político-militar em uma perspectiva geopolítica. $\mathrm{O}$ caráter transnacional dos desafios ambientais significa dizer que nenhum país está imune as suas consequências, ainda quando não tenha um papel protagonista na gênese destes, como, por exemplo, as mudanças climáticas, as condições hídricas e de saneamento.

Dessa forma,

[a] água ignora barreiras políticas, invade a classificação institucional e escapa às generalidades legais. Diante disso, as questões relacionadas a uma bacia transfronteiriça internacional devem ser analisadas por suas especificidades e por sua complexidade ${ }^{15(30)}$.

A bacia hidrográfica pode ser definida como uma unidade geográfica utilizada para os estudos sobre ciclo hidrológico e definida como

[...] uma área de captação da água de precipitação, demarcada por divisores topográficos, onde toda água captada converge para um único ponto de saída, o exutório. A bacia hidrográfica é um sistema físico onde podemos quantificar o ciclo de água15(116)

Nesse campo internacional, destaca

[...] a Convenção de Helsinque de 1992 inova ao aceitar o conceito de bacia hidrográfica (art. $\left.2^{\circ}, \$ 6 \div 16\right)$ e acolhe em seu texto os princípios da responsabilidade comum, porém diferenciada; da precaução; do poluidor pagador; e da responsabilidade intergeracional (art. 2ㅇ, $§ 5 \circ$ ). O texto da Convenção também traz medidas 
concretas de prevenção, controle e redução do impacto transfronteiriço (art. 3ㅇ) 15(39).

O conceito de bacia hidrográfica foi introduzido pelo Direito Internacional Público e consagrado no primeiro texto multilateral pela Convenção e Estatutos Relativos ao Desenvolvimento da Bacia do Chade assinada em Fort Many (Ndjamena) em 1964.

Nesse particular, destaca-se que:

Em 2000, o conceito de bacia hidrográfica foi incluído na Diretiva 2000/60 da Comunidade Européia: 'a área terrestre a partir da qual todas as águas fluem, através de uma sequência de ribeiros, rios e eventualmente lagos para o mar, desembocando numa única foz, estuário ou delta' (art. 2으, no 13). Neste caso, a Diretiva não se limita à bacia como unidade de gestão das águas. Cria uma entidade maior: a 'região hidrográfica', definida como 'a área de terra e de mar constituída por uma ou mais bacias hidrográficas vizinhas e pelas águas subterrâneas e costeiras que lhes estão associadas, definida nos termos do nำ1 do artigo 319 como a principal unidade para a gestão das bacias hidrográficas' (art. 2으, ํㅜ 15) 15(40).

Ainda no campo internacional, em 2004, o conceito de bacia hidrográfica é acolhido pela Conferência de Berlim, destacando-se os objetivos comuns de uma bacia hidrográfica internacional, sendo

[...] considerados em razão dos recursos naturais compartilhados, no caso específico a água superficial (rios e todas as fontes de água doce, como lagos, lençóis freáticos, águas de geleiras) e até da água subterrânea, cabendo no polêmico conceito de bacia hidrográfica integrada15(40).

O conceito de bacia hidrográfica tem sido cada vez mais estudado e utilizado como unidade de gestão e planejamento (Lei $\mathrm{n}^{\circ}$ $9.433 / 97)^{16}$, assim, repensar um conceito ampliado de fronteira, de acordo com as novas configurações da geopolítica geradas pelo fenômeno da globalização, implica definir a fronteira e a bacia hidrográfica em uma visão mais condizente com a realidade contemporânea, especialmente no que se refere a temas como saúde e saneamento.

\section{A fronteira Brasil-Uruguai, a bacia hidrográfica e o saneamento sem fronteiras}

Na perspectiva de um estudo hidrológico, o conceito de bacia hidrográfica envolve um conjunto de terras drenadas por um corpo d'água principal e seus afluentes e representa a unidade mais apropriada para o estudo qualitativo e quantitativo do recurso água, além de seus fluxos, sedimentos e nutrientes. A área de fronteira Brasil-Uruguai é formada por municípios de pequeno e médio porte e, na sua maioria, com a mesma vocação e problemas. Ela "tem uma extensão de 1.068,1 km e está perfeitamente 'demarcada' por marcos de fronteira”'17(55).

$\mathrm{Na}$ fronteira em análise, as articulações estabelecidas entre seus habitantes abrangem vários aspectos e acordos que foram sendo firmados sem constrangimentos entre seus habitantes e, principalmente, por meio das instituições que transformaram o espaço territorial em uma fronteira aberta. A Bacia Hidrográfica Mirim-São Gonçalo, localizada nos limites internacionais e considerada transfronteiriça, com regime de águas compartilhadas (Tratado de Limites de 1909 e Tratado da Lagoa Mirim de 1977), constitui-se um importante bem ambiental para ambos os países. Sua abrangência abarca recursos hídricos em uma superfície (aproximada) de $62.250 \mathrm{~km}^{2}$, sendo 29.250 $\mathrm{km}^{2}(47 \%)$ no Brasil e $33.000 \mathrm{~km}^{2}$ (53\%) no Uruguai. Em toda a Bacia, a Lagoa Mirim é o principal corpo d'água, possuindo uma área aproximada de $3.750 \mathrm{Km}^{2}$, sendo $82 \%$ no Brasil e $18 \%$ no Uruguai, constituindo-se o terceiro lago em extensão da América do Sul.

Cabe destacar que as ações de ambos os países têm como norte os termos do Tratado 
de Cooperação para o Aproveitamento dos Recursos Naturais; e o Desenvolvimento da Bacia da Lagoa Mirim - Decreto no 81.351, de 17 de fevereiro de 1978 - prevê a estreita colaboração entre os países para promover o desenvolvimento integral da Bacia da Lagoa Mirim, localizada na fronteira entre os dois países. Nesse contexto, cabe destacar a diferenciação político-administrativa dos dois países ante o saneamento.

No Brasil, as atribuições relacionadas com meio ambiente e saneamento estão a cargo de instituições como o Ministério do Meio Ambiente; Agência Nacional das Águas; Ministério do Desenvolvimento Regional; secretarias estaduais de meio ambiente; comitês e agências de bacias; concessionárias públicas e privadas de saneamento, além de órgãos municipais de meio ambiente, limpeza urbana e ainda o Ministério da Saúde que atribui à Funasa o papel de promover a saúde pública e a inclusão social por meio de ações de saneamento e saúde ambiental, especialmente em municípios com menos de 50 mil habitantes.

No Uruguai, essas atribuições recaem sob o Ministério de Vivienda, Ordenamiento Territorial y Medio Ambiente; Dirección Nacional de Medio Ambiente; Dirección Nacional de Águas; Obras Sanitarias del Estado (OSE) e; os Departamentos.

O saneamento pode ser compreendido como o serviço que abrange as ações relacionadas com abastecimento de água, o esgotamento sanitário, a limpeza urbana e o manejo de resíduos sólidos, drenagem e manejo das águas pluviais urbanas $\left(\operatorname{Lei~}^{0}{ }^{11.445 / 07}\right)^{17}$. Sua dimensão tem implicações diretas com outros fatores, como a questão cultural, ambiental, sanitária, estritamente ligados à saúde pública, dos direitos humanos, e é fundamental à sadia qualidade de vida.

É importante destacar que o Brasil é signatário da Declaração sobre o Direito ao Desenvolvimento, adotada pela Resolução ${ }^{\circ}$ 41/128 da Assembleia Geral das Nações Unidas, 1986. Esta Declaração, segundo seu art. $1^{\circ}$, item 1, dispõe que o direito ao desenvolvimento é um direito humano inalienável em virtude do qual toda pessoa humana e todos os povos estão habilitados a participar do desenvolvimento econômico, social, cultural e político, a ele contribuir e a dele desfrutar, no qual todos os direitos humanos e liberdades fundamentais possam ser plenamente realizados.

Ainda no bojo da Declaração sobre o Direito ao Desenvolvimento, em seu art. $8^{\circ}$, destaca-se:

\begin{abstract}
Os Estados devem tomar, a nível nacional, todas as medidas necessárias para a realização do direito ao desenvolvimento e devem assegurar, inter alia, igualdade de oportunidade para todos em seu acesso aos recursos básicos, educação, serviços de saúde, alimentação, habitação, emprego e distribuição equitativa de renda. Medidas efetivas devem ser tomadas para assegurar que as mulheres tenham um papel ativo no processo de desenvolvimento. Reformas econômicas e sociais apropriadas devem ser efetuadas com vistas à erradicação de todas as injustiças sociais ${ }^{19(04)}$
\end{abstract}

No plano internacional, três marcos abordam a temática do saneamento aprovados no âmbito da Organização das Nações Unidas. O primeiro refere-se aos Objetivos de Desenvolvimento do Milênio, firmados pelo Brasil e outros 190 países, em setembro de 2000, prevendo, entre outras metas relacionadas com o saneamento básico, a redução em $50 \%$, até 2015 , da parcela da população sem acesso à água potável e ao esgotamento sanitário no ano de 1990.

O segundo destaque é a Resolução A/ RES/64/292, da Assembleia Geral das Nações Unidas, de 28 de julho de 2010, apoiada por 122 nações, com 41 abstenções e nenhum voto contrário, com forte suporte da diplomacia brasileira, e que trata dos direitos à água e ao esgotamento sanitário. Ainda no plano internacional, diversos documentos apontam para a necessidade do acesso à água limpa e segura e ao esgotamento sanitário adequado como um direito humano, essencial para o pleno gozo da vida e de outros direitos humanos. 
Por fim, os Objetivos de Desenvolvimento Sustentável (ODS) do Programa das Nações Unidas para o Desenvolvimento (PNUD). Essa iniciativa dá origem ao documento 'Transformando Nosso Mundo: A Agenda 2030 para o Desenvolvimento Sustentável'. A Agenda é um plano de ação para as pessoas, o planeta e a prosperidade. Entre os 17 ODS, destaca-se o de número 6 - água potável e saneamento -, que tem por objetivo assegurar a disponibilidade e gestão sustentável da água e saneamento para todas e todos ${ }^{20(18)}$.

Entre suas metas, estão, até 2030, alcançar o acesso a saneamento e higiene adequados e equitativos para todos, e acabar com a defecação a céu aberto, com especial atenção para as necessidades das mulheres e meninas e daqueles em situação de vulnerabilidade; e até 2030, implementar a gestão integrada dos recursos hídricos em todos os níveis, inclusive via cooperação transfronteiriça, conforme apropriado ${ }^{20(25)}$. Nesse sentido, a Lei ${ }^{\circ}$ 9.433/97, que disciplina a Política Nacional de Recursos Hídricos, em seu art. $1^{\circ}$, I, dispõe que a água é um bem de domínio público.

No Uruguai, o serviço de distribuição de água e coleta de esgoto à população é um direito fundamental, segundo dispõe o art. 47 da Constituição. O controle de qualidade e administração dos serviços de águas e saneamento pertence ao Ministério dos Transportes e Obras Públicas (MTOP), desde a criação do Código das Águas em 1978 - Lei no ${ }^{\circ} 14.859$. O Código das Águas foi regulamentado pelo Decreto no 253/1979; e, em 1990, foi criado o Ministério da Habitação, Ordem Territorial e Meio Ambiente.

Quanto aos instrumentos de gestão, por exemplo, no Brasil, existem o Plano Nacional de Saneamento; os planos estaduais de recursos hídricos, bem como os planos de bacia hidrográfica e planos municipais de saneamento básico, com relações diretas com os desafios do saneamento.

A Constituição Federal de 1988 (CF/88) estabelece, em seu art. 21, ser competência da União elaborar e executar planos nacionais e regionais de ordenação do território e de desenvolvimento econômico e social e "instituir diretrizes para o desenvolvimento urbano, inclusive habitação, saneamento básico e transportes urbanos"21(20-21).

Complementando, a Lei ${ }^{0} 10.257 / 2001$, em seu art. $2^{\circ}$, traz como diretriz da Política Urbana garantia, entre outros, do direito ao saneamento e estabelece, também, a competência da União nas questões da Política Urbana. Em seu art. $3^{\circ}$, o saneamento básico está incluído no rol de atribuições de interesse da política urbana, e, nesse sentido, a elaboração do Plano Nacional de Saneamento Básico (Plansab), cuja elaboração foi prevista na Lei $\mathrm{n}^{\circ} 11.445 / 2007$, que resultou em um processo planejado e coordenado.

Entre as características de formulação e elaboração do Plansab, encontram-se os princípios norteadores, sendo a universalização, a equidade, a integridade, a intersetorialidade, a sustentabilidade, a participação e controle social ou a democratização da gestão dos serviços e a matriz tecnológica.

No Uruguai, o recente Plano Nacional de Aguas (2017) institui uma série de desafios quanto aos temas relacionados com o meio ambiente, a água e o saneamento. De acordo com o Plan Nacional de Aguas

El agua es un derecho humano fundamental. Es esencial para la vida humana y para la de todas las especies que habitan el planeta, y un elemento clave en cada una de las actividades que se realizan en el. Es un recurso limitado y por esa razón necesita un tratamiento especial. Por ello el Estado tiene responsabilidades ineludibles en relación al agua: proteger su calidad, garantizar su cantidad y asegurar el acceso ${ }^{22(07)}$.

O sistema legislativo uruguaio de gestão, controle, fiscalização e regulação da Política de Saneamento Básico conflita com a privatização do serviço que, em 1999, na municipalidade de Maldonado, acarretou problemas sociais, motivando protestos contra a privatização do serviço. 
Entre os objetivos do referido Plano, ganham destaque:

Garantizar a los habitantes el ejercicio de los derechos humanos fundamentales de acceso al agua potable y al saneamiento.

La primera prioridad para el uso del agua es el abastecimiento de agua potable a poblaciones y la prestación del servicio de agua potable y saneamiento deberá hacerse anteponiendo las razones de orden social a las de orden económico.

Disponer de agua en cantidad y calidad para el desarrollo social y económico del país y para la conservación de la biodiversidad y el funcionamiento de los ecosistemas mediante la gestión integrada y participativa.

Prevenir, mitigar y adaptarse a los efectos de eventos extremos y al cambio climático, com enfoque en la gestión de riesgo ${ }^{22(10)}$.

A área de fronteira confinada a rígidos padrões de segurança nacional, materializados em legislação e políticas governamentais ao longo de décadas, contrapõe-se à necessária flexibilidade exigida pelas políticas de saúde e proteção ambiental. No Brasil, a temática transfronteiriça torna-se vital, quando se analisa que, além dos milhares de quilômetros de fronteiras terrestres e divisas com 10 outras nações, cerca de $60 \%$ do território nacional está inserido em bacias hidrográficas que se estendem pelos territórios de países vizinhos, e reúnem 83 rios fronteiriços ou transfronteiriços $^{3}$. Assim, as decisões e implantação de projetos nessas áreas, sejam ambientais ou econômicos, são de âmbito ministerial.

Desse modo, torna-se importante

[...] refletir sobre a situação de municípios fronteiriços, assim como observar iniciativas de cooperação, contribui no MERCOSUL para análises específicas de repercussões da integração nos sistemas de saúde, e pode influir na pauta de acordos e programas voltados para regiões fronteiriças, apoiar esforços de garantia de atenção integral e humanizada, e para o fortalecimento das políticas nacionais de saúde 23(249)

O fluxo migratório em busca de atenção em saúde, por exemplo, tem gerado dificuldades para os gestores públicos municipais brasileiros, bem como para as autoridades dos países vizinhos, além de previsíveis problemas diplomáticos e de saúde pública. O reconhecimento dos problemas de saúde ambiental decorrentes da degradação e contaminação do meio ambiente requer, em muitos casos, soluções que ultrapassam as fronteiras dos Estados.

\section{Considerações finais}

O presente trabalho se constitui mais uma etapa importante das pesquisas sobre planejamento, gestão ambiental e saneamento em áreas de fronteira, especialmente na área de abrangência da Bacia Hidrográfica da Lagoa Mirim (Brasil-Uruguai). A referida pesquisa é um estudo inédito sobre saneamento em uma perspectiva transfronteiriça.

As pesquisas relacionadas com os temas meio ambiente, saúde e saneamento em áreas de fronteira, especialmente na área de abrangência da Bacia Hidrográfica Transfronteiriça da Lagoa Mirim, no extremo sul da América do Sul, necessitam ser intensificadas. Os fatores que permeiam as áreas supracitadas adquirem uma perspectiva própria por se contextualizarem em uma área de fronteira entre países, interessando, assim, pontuar a complexidade que se expressa no processo de construção das ações cooperadas entre os diferentes atores e instituições locais, regionais e nacionais.

Como evidenciado, a área de fronteira entre Brasil e Uruguai apresenta enorme proximidade em manifestações culturais, mas, por outro lado, cada localidade, ao longo da fronteira seca que 'une' e 'separa' o Brasil e o Uruguai, tem conformações distintas e 
características próprias, de acordo com as suas especificidades.

Assim, os pressupostos da cooperação entre os povos para o progresso da humanidade e da integração econômica, política, social e cultural dos povos da América Latina exige dos planejadores e gestores públicos das áreas de saúde, meio ambiente e saneamento em áreas fronteiriças melhor articulação e implementação de ações e projetos sob as diversas peculiaridades político-administrativas. A identificação de atores envolvidos e a verificação dos termos da cooperação político-social e da possível coexistência de interesses diversos desafiam a matriz vigente das organizações públicas e privadas, ao problematizar a transfronteiricidade dos desafios da saúde ambiental e do saneamento.

Contudo, interessa evidenciar, neste momento, a ênfase que adquire a concepção de área ou região de fronteira, em detrimento de um enfoque restrito a uma concepção linear, característica da noção de limite ou divisão internacional. A transnacionalidade das questões sanitárias e ambientais de defesa e promoção do desenvolvimento sustentável evoluiu bastante, sobretudo nos últimos 20 anos, mas há um baixo nível de poder de implementação dessas normas e princípios em áreas de fronteira.

Nesse sentido, cabe destacar que a Conferência das Nações Unidas sobre Desenvolvimento Sustentável, Rio+20, quando estabelece entre seus objetivos centrais o debate e a proposição de soluções para a governança internacional em torno do desenvolvimento sustentável. O desenvolvimento de estratégias de cooperação transfronteiriça, que possibilitem a implementação de condições básicas de saneamento em áreas de fronteira, resultaria em crescimento econômico com justiça social, bem como um processo mais amplo do desenvolvimento sustentável nessas áreas. $\mathrm{O}$ uso da unidade bacia hidrográfica remete a um compromisso de abordagem interdisciplinar essencial para atingir o desenvolvimento sustentável.

A relação entre saneamento e saúde ambiental, principalmente nas áreas de fronteira, integra uma teia complexa de influências mútuas condicionadas por aspectos geográficos, econômicos, jurídicos, políticos e socioculturais, que se expressam nas inúmeras relações que a sociedade estabelece com os recursos naturais, de modo especial com a água, por exemplo, relações estas que necessitam ser mais bem exploradas, considerando a interface saúde/ambiente interligadas no processo de desenvolvimento transfronteiriço.

\section{Colaboradores}

Silva MPS (0000-0002-1178-132X)*, Assumpção RF (0000-0001-8257-3950)*, Kligerman DC (0000-0002-7455-7931)* contribuíram igualmente na elaboração do manuscrito. 


\section{Referências}

1. Silva MP. Governança Territorial em áreas de fronteira: um estudo sobre as políticas de saúde e meio ambiente em Santana do Livramento (Brasil) e Rivera (Uruguai). [tese]. Santa Cruz do Sul: Universidade de Santa Cruz do Sul; 2016. p. 152.

2. Claval P. O papel dos rios internacionais no diálogo regional: os casos do Reno e do Saint-Laurent. In: A Nuñes, Padoin MM, Oliveira TCM, organizadores. Dilemas e diálogos platinos. Dourados: UFGD; 2010. p. 39-58.

3. Brasil. Secretaria de Assuntos Estratégicos da Presidência da República Federativa do Brasil. Água e Desenvolvimento Sustentável - Recursos Hídricos Fronteiriços e Transfronteiriços do Brasil. Brasília, DF, 2013. [acesso em 30 jul 2019]. Disponível em http://www.sae.gov.br/site/wp-content/uploads/ Publica\%C3\%A7\%C3\%A3o-\%C3\%Algua_SAE.pdf.

4. Minayo M. O desafio do conhecimento: pesquisa qualitativa em saúde. 9. ed. São Paulo: Hucitec; 2006.

5. Coelho PMP. Fronteiras na Amazônia: um espaço integrado. Brasília, DF: Fundação Alexandre de Gusmão; 1992.

6. Nogueira RJB. Fronteira: Espaço de Referência Identitária? Ateliê Geográfico. 2007 [acesso em 2020 fev 28]; 1(2):27-41. Disponível em http://www.revistas. ufg.br/index.php/atelie/article/view/3013/3051.

7. Machado LO. Limites, Fronteiras, Redes. In: Strohaecker TM, Damiani A, Schaffer NO, et al., organizadores. Fronteiras e espaço global. Porto Alegre: Associação dos Geógrafos Brasileiros; 1998. p. 41-49.

8. Mélo JLB. Reflexões conceituais sobre fronteira. In: Castello IR, Koch MR, N Oliveira, et al. Fronteiras na América Latina: espaços em transformação. Porto Alegre: UFRGS; 1997. p. 68-74.

9. Mesquita Z. Procura-se o coração dos limites. In: Castello IR, Lehnen AC, Shaffer NO. Fronteiras no MERCOSUL. Porto Alegre: UFRGS; 1994, p. 69-73.
10. Mendonça ND. O impacto da fronteira sobre a vida das pessoas de uma comunidade - Santana do Livramento/Rivera. [dissertação]. Porto Alegre: Pontifícia Universidade Católica do Rio Grande do Sul Porto; 1980. p. 216.

11. Sarquis P. La educación em zonas de fronteira: píntese de investigaciones realizadas em Argentina. In: Trinidade AM, Behares LE, organizadores. Fronteiras, Educação, Integração. Santa Maria/RS. Santa Maria: Pallotti; 1996. p. 43-75.

12. Brasil. Ministério da Integração Nacional. Proposta de reestruturação do programa de desenvolvimento da faixa de fronteira. Bases de uma política integrada de desenvolvimento regional para a faixa de fronteira. Brasília, DF: Ministério da Integração Nacional; 2005.

13. Martin AR. Fronteiras e Nações. São Paulo: Contexto; 1994.

14. Haesbaert R. Dos Múltiplos Territórios à Multiterritorialidade. Anais do I Seminário Nacional sobre Múltiplas Territorialidades. Porto Alegre: ULBRA AGB. p. 3; 2004.

15. Cibim JC. O desafio da governança nas bacias hidrográficas transfronteiriças internacionais: um olhar sobre a Bacia do rio da Prata. [tese]. São Paulo: Universidade de São Paulo; 2012. p. 189.

16. Brasil. Lei ${ }^{\circ}$ 9.433, de 8 de janeiro de 1997. Institui a Política Nacional de Recursos Hídricos, cria o Sistema Nacional de Gerenciamento de Recursos Hídricos, regulamenta o inciso XIX do art. 21 da Constituição Federal, e altera o $\operatorname{art.~}^{\circ}$ da Lei n ${ }^{\circ} 8.001$, de 13 de março de 1990, que modificou a Lei ${ }^{\circ}$ 7.990, de 28 de dezembro de 1989. Diário Oficial da União. 9 Jan 1997.

17. Brasil. Lei ${ }^{\circ}$ 11.445, de 5 de janeiro de 2007. Estabelece diretrizes nacionais para o saneamento básico; altera as Leis nos 6.766, de 19 de dezembro de 1979, 8.036, de 11 de maio de 1990, 8.666, de 21 de junho 
de 1993, 8.987, de 13 de fevereiro de 1995; revoga a Lei no 6.528, de 11 de maio de 1978; e dá outras providências. Diário Oficial da União. 8 Jan 2007.

18. Navarrete M. Región Fronteiriza Uruguayo - Brasileira/Laboratório social para la intregración regional: cooperación e integración transfronteiriza. [dissertação]. Montevideo: Universidad de la República; 2006. p. 69

19. Organização das Nações Unidas. Declaração sobre o Direito ao Desenvolvimento. 1986. [acesso em 2020 jan 20]. Disponível em: http://pfdc.pgr.mpf.mp.br/ atuacao-e-conteudos-de-apoio/legislacao/direitos-humanos/decl_direito_ao_desenvolvimento.pdf.

20. Organização das Nações Unidas. Transformando Nosso Mundo: A Agenda 2030 para o Desenvolvimento Sustentável. [acesso em 2020 jan 20]. Disponível em: http://www.agenda2030.org.br/saiba_mais/publica- coes.

21. Brasil. Constituição da República Federativa do Brasil de 1988. 41. ed. Edição atualizada e ampliada. São Paulo: Saraiva; 2008.

22. República Oriental do Uruguai. Ministério de Vivienda Ordenamiento Territorial y Meio Ambiente (MVOTMA). Plan Nacional de Águas, 2017. p. 320.

23. Guimarães L, Giovanella L. Municípios brasileiros fronteiriços e Mercosul: características e iniciativas de cooperação em saúde. Saúde debate. 2005; 29(71):248-257

Recebido em 25/04/2019 Aprovado em 24/07/2019

Conflito de interesses: inexistente

Suporte financeiro: não houve 